\title{
Parsiyel rotator manşet yaralanmalarının artroskopik tamiri ve klinik sonuçları
}

\author{
Arhroscopic repair of partial rotator cuff tears and the clinical outcomes
}

\author{
Mehmet E. Erdil, İrem Hazal İnan, Onur Tunalı
}

Acıbadem Üniversitesi Tıp Fakültesi, Ortopedi ve Travmatoloji Ana Bilim Dalı, İstanbul

\begin{abstract}
Omuz eklemi vücudun en geniş hareket açıklığına sahip olan eklemi olduğundan omuz ekleminin her bir patolojisi omuz hareketlerini ve fonksiyonlarını kısıtlayarak yaşam kalitesini düşürmektedir. Rotator manşet kasları; dinamik stabilitazörler olan supraspinatus, infraspinatus, subskapularis ve teres minör kaslarından oluşur. Statik stabilitazörler olarak bilinen biseps-labral kompleks ve glenohumeral ligaman ile birlikte omuz ekleminin hareket ve stabilitesinde önemli bir rol oynar. Rotator manşet yırtıkları, ileri yaş aktiviteleri arttıkça ve insan ömrü uzadıkça ortopedik cerrahların karşısına daha sıklıkla çıkmaktadır. Rotator manşet yırtığında hastaların geliş nedeni sıklıkla ağrıdır. Manyetik rezonans (MR) günümüzde hem tanıda hem de tedavi sonrası takipte oldukça sık başvurulan bir yöntemdir. Rotator manşet yırtıklarının tedavisinde konservatif ve cerrahi yöntemler yer alır. Konservatif tedaviye rağmen yırtıkta zaman içinde iyileşme görülmemesi, bilinen semptomlara ağrı ve hareket kaybının da eklenmeye başlaması, konservatif tedaviden artık uzaklaşmak gerektiğine işaret eder. Son yıllarda rotator manşet yırtıklarının cerrahi tedavisinde en sık kullanılan yöntem artroskopik tamirdir. İyi tedavi edilmiş bir manşet yırtığının klinik sonuçları oldukça yüz güldürücüdür.

Anahtar sözcükler: rotator manşet; rotator manşet yırtığı; artroskopik cerrahi
\end{abstract}

\begin{abstract}
Since the shoulder joint has the widest range of motion in the body, each pathology of the shoulder joint reduces the quality of life by limiting shoulder movements and functions. Rotator cuff muscles consist of the supraspinatus, infraspinatus, subscapularis and teres minor muscles, which are dynamic stabilizers; together with the biceps-labral complex and glenohumeral ligament, known as static stabilizers, they play an important role in the movement and stability of the shoulder joint. Rotator cuff tears are encountered more frequently by orthopedic surgeons as advanced age activities increase and life expectancy increases. Pain is the most common admission cause of the orthopedic surgeon. Magnetic resonance imaging (MRI) is the gold standard for diagnosis of rotator cuff tears. Treatment includes conservative and surgical methods. The fact that the tear does not improve over time despite conservative treatment and symptoms such as pain and loss of range of motion indicate that it is time to discuss surgical treatment options. Arthroscopic repair is the most commonly used method in the surgical treatment of rotator cuff tears in recent years. The clinical results of a well-treated cuff tear will be quite satisfactory.
\end{abstract}

Key words: rotator cuff; rotator cuff tears; arthroscopic surgery

yırtıklardır. Ayrıca belirli bir yaştan sonra dejeneratif rotator manşet yırtıkları omuz ağrılarının önemli bir sebebidir. ${ }^{[1]}$

Codman, rotator manşet lezyonlarına modern yaklaşımın öncüsü olarak bilinir. 1934 yılında ABD'de yayınlanan "The Shoulder" adlı kitabında rotator manşete ait tendonların patolojik değişiklikleri, rotator manşet yırtıklarının sıklığı, belirtileri, bulguları ve tedavi yöntemleri kapsamlı bir şekilde anlatılmıştır. Dünyada ilk rotator manşet tamiri 1909 yılında Codman tarafından gerçekleştirilmiştir. ${ }^{[1]}$

İletişim / Contact: Prof. Dr. Mehmet E.Erdil•E-posta / E-mail: drmehmeterdil@gmail.com.

ORCID iD: Mehmet E.Erdil, 0000-0003-4637-9426 • İrem Hazal İnan, 0000-0001-7738-0281 • Onur Tunalı, 0000-0002-7808-9426

Geliş / Received: 28 Ocak 2022 • Kabul / Accepted: 3 Şubat 2022 
Rotator manşet kasları; dinamik stabilitazörler olan supraspinatus, infraspinatus, subskapularis ve teres minör kaslarından oluşur. Statik stabilitazörler olarak bilinen biseps-labral kompleks ve glenohumeral ligaman ile birlikte omuz ekleminin hareket ve stabilitesinde önemli bir rol oynar. Biseps tendonu uzun başı, rotator manşetin bir üyesi olmamakla birlikte, fonksiyonel olarak bu grubun içinde yer alır. Rotator manşet yırtıklarına rotator interval içerisinde bulunan biseps uzun başı lezyonları da genellikle eşlik eder. Rotator manşet patolojileri; basit bir aşırı kullanımdan, sıkışma sendromu, parsiyel yırtık, tam kat yırtık ve yırtığın ileri aşamasında ise rotator manşet yırtığı artropatisi olarak karşımıza çıkabilmektedir. Parsiyel rotator manşet yırtıklarının cerrahi dışı tedavilerinin başarısız olması durumunda artroskopik tamiri önerilen tedavi yöntemidir.

\section{TANI}

Rotator manşet yırtığında hastaların geliş nedeni sıklıkla ağrıdır. Ağrının yeri ve yayılımı mutlaka sorgulanmalı, hastadan ağrının yerini göstermesi istenmelidir. Ardından gözle deltoid ve rotator manşet kasları izdüşümlerinde atrofi, şişlik, subluksasyon gibi durumların var olup olmadığı izlenmelidir. Her iki omuzun simetrisi incelenmelidir. Palpasyonla ağrı tam lokalize edilmeye çalışıımalıdır. Ayırıcı tanı için bu lokalizasyon önemlidir. Ayrıca servikal problemlerin omuza yansıyacağı akılda tutularak boyun muayenesi yapılmalıdır. Hastanın ağrısını provoke etme yöntemiyle çalışan birtakım manevraları içeren muayene testleri yapılmalı ve omuz hareket genişliği değerlendirilmelidir. Testler çok çeşitlidir ve her bir tendon ve yapı için tanımlanmış testler mevcuttur.

Direkt radyografi rotator manşet yırtıklarının tanısında oldukça yardımcıdır; ayırıcı tanı için de gereklidir. Ön arka omuz grafisi, skapula Y grafisi, supraspinatus çıkım grafisi ve lateral aksiller radyografi ilk istenmesi gereken radyolojik tetkikler olmalıdır. Bu radyografilerde tüberkulum majusta skleroz olması, subakromial alanda çıkıntı olması, akromiohumeral eklem mesafesinde azalma gibi ikincil bulgular manşet yırtığını akla getirmelidir. Bu grafiler iyi bir muayene ile eşleştirilirse doğru tanıya yaklaşılabilir.

Manyetik rezonans (MR) günümüzde en sık kullanılan tanı yöntemidir. Hem tanıda hem de tedavi sonrası takipte oldukça sık başvurulan bir yöntemdir. Tendonları ayrı ayrı ortaya koyabildiği gibi tendondaki yırtık derecesini, tendonun ne kadar geriye kaçtığını, yağlı dejenerasyona uğrayıp uğramadığını MR sayesinde görebiliriz. Artro MR yöntemiyle daha küçük ve kısmi yırtıkların tespiti daha kolay hâle gelebilir.

Bilgisayarlı tomografi (BT) ise manşet yırtığı artropatisinde kemik kaybının derecesini görme açısından kullanışlıdır. Ayrıca rotator manşet kasları yağlı dejenerasyo- nunu ortaya koyan Goutallier sınıflandırması BT temelli bir sınıflandırmadır. Bu sınıflandırma sayesinde yırtığın tamir edilip edilemeyeceği değerlendirilebilir. ${ }^{[2]}$

Aslında rotator manşet yırtıklarının kullanılan tek bir sınıflandırması yoktur. Ayrıca sınıflandırmayı yırtığın derinliğine, etiyolojisine, oluş zamanına, büyüklüğüne, şekline, eşlik eden tendon sayısına, yırtığın yerleşimine ve tendonun kalitesine göre yapabiliriz. Rotator manşet yırtıklarının cerrahi onarımlarının sonuçlarını bildiren çeşitli çalışmalar arasında, bir sınıflandırma sisteminin olmaması nedeniyle karşılaştırma yapmak çok zordur. Patte tarafından önerilen bir sınıflandırma sistemi, yırtığın boyutunu, sagital ve ön düzlemlerdeki topografisini, kasın kalitesini ve biseps uzun başının bütünlüğünü hesaba katmaktadır. ${ }^{[3]}$ Bu çalışmada, Patte Grup 1 parsiyel rotator manşet yırtıklarını inceleyeceğiz.

\section{TEDAVi}

Rotator manşet yırtıklarının tedavisinde konservatif ve cerrahi yöntemler yer alır. Hastanın yaşına, yırtığın boyutuna ve yırtık bölgesindeki atrofinin derecesine bağlı olmakla birlikte, tedavi yöntemleri arasında konservatif tedavi de yerini almıştır. ${ }^{[4]}$ Konservatif tedavinin temelini, kişinin günlük yaşam aktivitelerini kolaylaştırmaya yönelik uğraşı terapileri, kas gücünün ve eklem hareket açıklığının geliştirilmesine yönelik egzersiz programları oluşturmaktadır. ${ }^{[5]}$ Yaklaşık üç ay konservatif tedaviye rağmen cevap alınamayan olgularda cerrahi tedavi endikedir. Konservatif tedaviye rağmen yırtıkta zaman içinde iyileşme görülmemesi, bilinen semptomlara ağrı ve hareket kaybının da eklenmeye başlaması, konservatif tedaviden artık uzaklaşmak gerektiğine işaret eder.

Cerrahi tedavinin nasıl olacağını belirlemeden önce, tedavide nelerin gerektiğini bilmek gerekir. Yırtık kenarlarının fibrotik ve avasküler hale gelmiş olması nedeniyle tamir sahasında vasküler bir kemik yatağının hazırlanması ve yırtık kenarlarının tazelenmesi gereklidir. Yırtığın mediale doğru supraspinatus, öne doğru subskapularis ve arkaya doğru infraspinatus tarafından çekilmekte olduğu düşünüldüğünde, tamir bittiğinde kol vücudun yanında adduksiyondayken tamir sahasının gergin olmaması gerekir. Gerginlik olmadan yırtık kenarlarının uç uca getirilerek tamiri ve son olarak hazırlanan kemik yatağına sabitlenmesiyle rotator kaslar arasındaki devamlılık sağlanmış olur.

Günümüzde cerrahi yöntem olarak açık rotator manşet onarımının popülaritesi azalmış olup son yıllarda en sık kullanılan yöntem artroskopik tamirdir. Artroskopik olarak rotator manşet yırtıklarının tedavisinde, öncelikle ideal görüntü için, omuz artroskopisinin uygun giriş noktalarından ve uygun biçimde yapılması gerekir. Yırtığa 
ulaşmak için portal giriş yerleri ve alternatifleri bilinmelidir. Küçük ya da orta büyüklükteki rotator manşet yırtıkları daha büyük yırtıklardan daha iyi klinik sonuçlar ve yapısal iyileşme göstermiş olsa da, iyileşme başarısızlığı devam etmektedir ${ }^{[6]}$ Artroskopik tedavide ilk baştan bu yana kullanılmakta olan ve standart dikiş yöntemi halini alan tek sıra dikiş tamir yönteminde başarılı sonuçlar bildirilmiştir ancak hasta memnuniyeti iyi olmasına rağmen, tekrar yırtılma riskinin fazla olduğunun gösterilmesi ve tendonun anatomik yapışma yerinin tam kapatılamıyor olması gibi nedenlerden dolayı, çift sıra dikiş tamir yöntemi ortaya çıkmıştır. ${ }^{[7]}$ Her ne kadar kadavra çalışmalarında çift sıra dikiş yönteminin biyomekanik olarak daha güçlü olduğu gösterilmişse de, klinikte fonksiyonel açıdan tek sıra dikiş yöntemiyle arasında anlamlı bir farklılık bulunamamıştır. ${ }^{[8,9]}$ Cerrahi tedavi sonuçlarını etkileyen faktörler arasında; erkek cinsiyet, genç yaşta tamir, yüksek kemik mineral yoğunluğu, diyabet eşlik etmemesi, yüksek aktivite düzeyi, ameliyat öncesi yüksek eklem hareket açıklığı, düşük vücut kitle indeksi, lezyon boyutunun küçük olması ve yağlı dejenerasyon olmaması iyi faktörler olarak belirlenmiştir. ${ }^{[10,11]}$

Ameliyata başlamadan önce hasta ve cerrahi ekibe göre en optimal cerrahi pozisyon belirlenmelidir. Hastaya özgü klinik durumlar da göz önünde bulundurularak şezlong veya lateral dekubit pozisyon tercih edilebilir ancak lateral dekubit pozisyonun pulmoner emboli açısından daha yüksek risk barındırdığını raporlayan birçok retrospektif çalışma vardır. ${ }^{[12,13]}$ Biz kliniğimizde şezlong pozisyonunu tercih ediyoruz. Pozisyon vermeden önce tercihen interskalen blok yapılabilir.

Omuz artroskopisine başlamadan önce ilk adım olarak kemik izdüşümleri cilt üzerine çizilmelidir. Bu uygulama, portallere kolayca hakim olunabilmesine yardım eder. Steril bir işaretleyici kalem (marker) ile yardımıyla skapular çentik, distal klavikulanın anterior ve posterioru ile akro- mioklavikular (AK) eklem çizilir. Korakoid çıkıntı (proses) bulunarak işaretlenir.

Akromion posterolateral köşesinin $20 \mathrm{~mm}$ inferioru ve 15-20 mm medialinden posterior portal açılır. Posterior portal yaygın olarak görüntüleme portali olarak kullanılır. Bir iğne yardımıyla doğrultu belirlenebilir ve trokar korakoid prosese yönlendirilerek girilir. Hasta şezlong pozisyonundaysa abduksiyon ve lateral traksiyon uygulanması posterior kapsülün gerilmesini sağlayarak portalin açımasını kolaylaştırabilir. Portalin inferiorunda aksiller sinir, medialde supraskapuler sinir ve arter bulunduğu unutulmamalıdır. Posterior portal açılmasının ardından anterior santral, antero-inferior ve antero-superior portaller tercihe ve yaklaşılacak yırtık bölgesine göre dışardan bir iğne yardımıyla belirlenebilir. Lateral giriş; akromiyonun anterior kenarının 10-15 mm posterioruna ve akromiyon kenarının yaklaşık 2-4 mm lateraline açılır. Bu giriş açılırken aksiler sinire dikkat edilmelidir. Lateral girişin yeri, artroskop subakromiyal alana sokulduktan sonra, bir spinal iğne ile belirlenmelidir. Spinal iğne rotator manşet yırtığının anterior ve posterior kenarları arasındaki uzaklığın ortasında olacak şekilde yerleştirilmelidir. ${ }^{[14]}$ Artroskopik girişimler için günümüzde $30^{\circ}, 70^{\circ}$ ya da farklı açılarda lensler kullanılmaktadır. Kullanım kolaylığına göre nörovasküler yapılara hasar vermeden ek portaller açılır. Kol abduksiyona, internal ve eksternal rotasyona alınarak tüm rotator manşet değerlendirilir. Saçaklanmalar varsa bu saçaklanmalar, tendon yaralanmasının büyüklüğünü değerlendirebilmek için normal dokuya kadar debride edilmelidir. Yapıları daha net görüntülemek için radyofrekans probu ile yumuşak dokular temizlenebilir. Total veya subtotal bursektomi gereğinde yapılmalıdır. Parsiyel yırtıklarının artroskopik tanısı yırtığın ekleme açılan veya bursal yüzeye açılan yırtık olması durumuna göre konulur. Parsiyel yırtık bulunduktan sonra tam kat haline getirilen yırtık özel dikişlerle tamir edilir (Şekil 1). Yırtık bölgesi ortaya konup

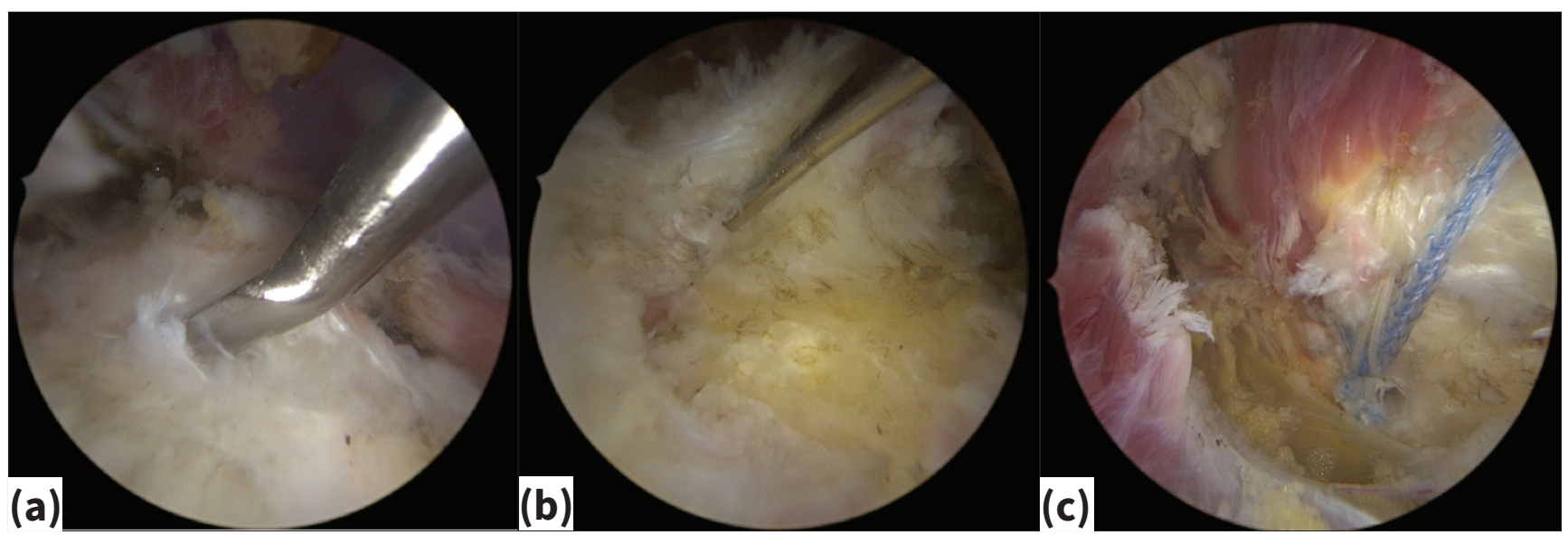

Şekil 1.a-c. Parsiyel supraspinatus yırtığı (a). Parsiyel yırtığın tam kata çevrilmesi (b). Yırtığın tamiri (c). 


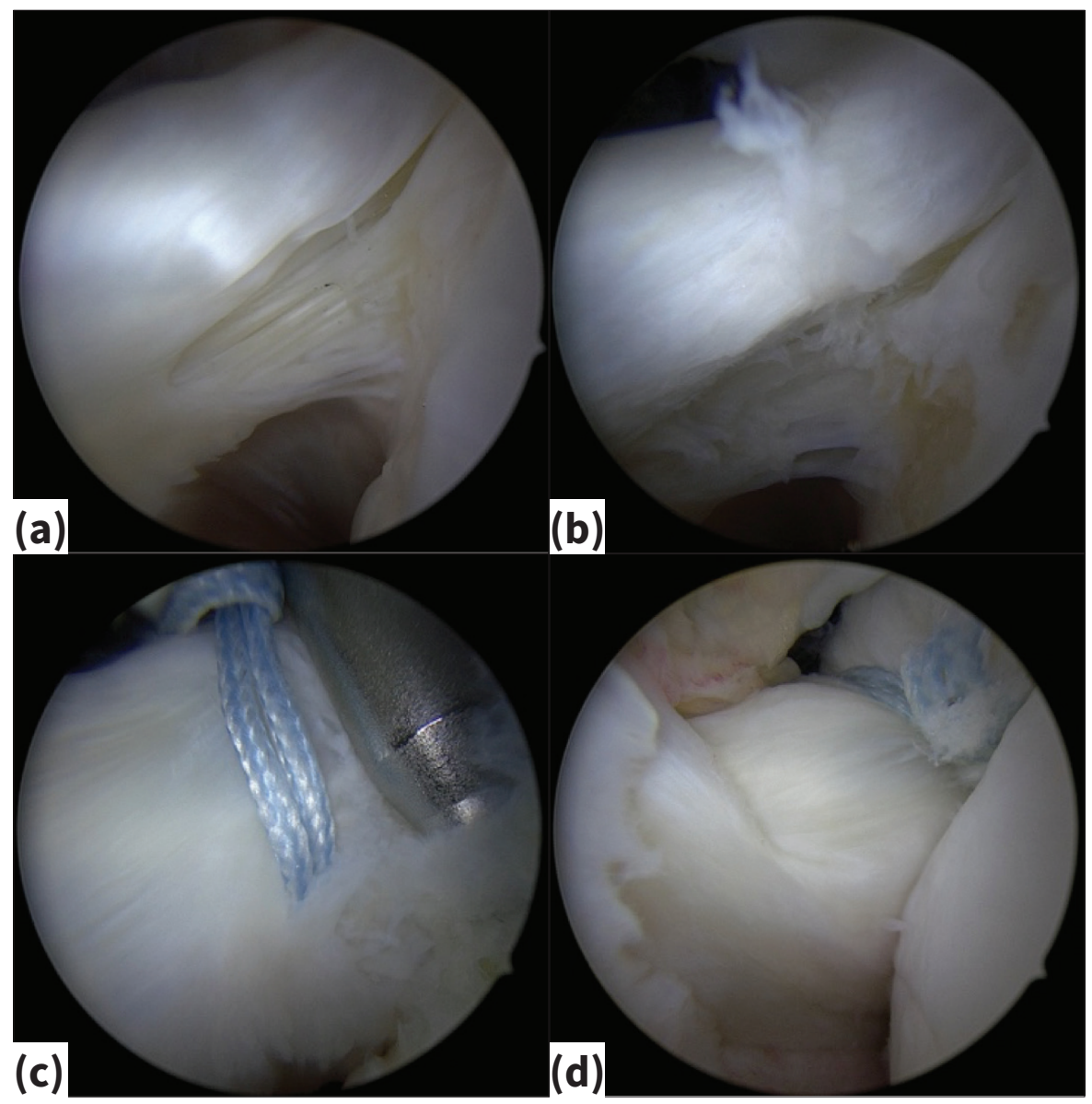

Şekil 2.a-d. Parsiyel subskapularis yırtığı (a). Parsiyel subskapularis yırtık ayak izinin hazırlanması (b). Subskapularisten düğümlerin geçilmesi (c). Yırtığın düğümsüz ankor ile tamiri sonrası görünüm (d).

dikiş yerleri belirlendikten sonra tamir işlemine geçilir (Şekil 1.c). Alternatif olarak parsiyel yırtık tam kat yırtığa dönüştürülmeden yapılan tamir teknikleri de tanımlanmıştır (Şekil 2). ${ }^{[15]}$

Anterolateral giriş deliğine şeffaf kanül yerleştirilir. Bu kanül, aletlerin ve iplerin subakromiyal alana sokulup çıkartılması için kullanıır. Drillemeyi yapmak ve çapaları yerleştirmek için ikinci bir lateral giriş yeri daha superiorda olacak şekilde açılır. Çapalar sıyrılmaya karşı dirençli olmaları için $45^{\circ}$ açıyla yerleştirilmelidir. Yırtık tamiri, kol abduksiyondayken yapılmamalıdır; çünkü kol hastanın gövdesinin yanına geri getirildiğinde, yapılan tamire aşırı yük binecek ve dolayısıyla tekrar yırtık oluşacaktır. ${ }^{[16]}$ Çapalar yerleştirildikten sonra mutlaka iplerden çekilerek tutma gücü kontrol edilmelidir. Atılacak düğümün şekli cerrahın seçimine bağlıdır. Dikişlere tutturulan tendonlar çapalar yardımıyla kemiğe sabitlenir ve tendondaki defekt kapatılır. Çapaların temel fonksiyonu tedavi edilmesi planlanan dokunun iyileşmesi tamamlanana kadar destek görevi sağlamaktır. Üretildikleri malzeme, yerleştirilme şekilleri, düğüm gereklilikleri, yüklenmiş ip sayısı ve dizaynlarına göre birbirinden farklı çapa çeşitleri bulunmaktadır. Cerrahın tecrübesine ve tercihine göre tamirde kullanılacak çapa belirlenir. Her bir çapa ve sütür geçirildikten ve bağlandıktan sonra iplerin kesilmesi birbirlerine karışmalarını önler. Bu teknik tek sıra tamir tekniğidir. Çift sıra rotator manşet onarım teknikleri, onarım konfigürasyonunda medial ve lateral sıra sütür ankoru içerir. ${ }^{[17]}$ Çift sıra tamir yönteminde medial sıra çapalar yerleştirilip düğümlendikten sonra kalan ipler tüberkülüm majusun 10-15 mm lateraline yerleştirilen iki adet dügümsüz çapayla tespit edilir.

Hastalar ameliyat sonrası üç hafta abduksiyon destekli omuz askısıyla takip edilir. Üçüncü hafta pasif egzersiz, altıncı hafta aktif egzersizler başlanır. Bu sırada dirsek ve el bileği hareketlerinin normal olarak yapılması hastaya anlatılır.

Artroskopi tekniklerinde ve dikiş materyeli teknolojilerinde gelişmeyle birlikte masif yırtıklarda bile \%88'e varan iyi ve mükemmel sonuçlar bildirilmiştir. ${ }^{[18]}$ Artroskopik rotator manşet tamirinin artmasına paralel olarak görü- 
len komplikasyonlar da artmaktadır. Artroskopik rotator manşet tamiri sonrası komplikasyon oranı yaklaşık \%10 olarak rapor edilmiştir. ${ }^{[19]}$ Komplikasyonlar arasında eklem sertliği, iyileşmeme, enfeksiyon, refleks sempatik distrofi ve derin ven trombozu görülmüştür. Yapılan başka bir derleme çalışmasında en sık karşılaşılan komplikasyon olarak onarımın anatomik başarısızlığı gösterilmiştir. ${ }^{[20]}$ Başarılı sonuçlarına rağmen rotator manşet tamiri zamanla revizyon gerektirebilmektedir. Revizyon nedenleri arasında başarısız rotator manşet onarımı, cerrahi komplikasyonlar, tanı hataları, teknik hatalar, iyileşme başarısızlığı ve travmatik başarısızlıklar gösterilebilir. ${ }^{[21,22]}$ Ayrıca yapılan başka bir çalışmada, revizyon rotator manşet onarımları arasında başlangıçta ihmal edilmiş subskapularis tendon yırtığının olduğu bildirilmiştir. ${ }^{[23]}$ Tekrar yırtık oluşma ve yeniden ameliyat gerekliliğini arttıran risklerden biri ise sigaradır. ${ }^{[24]}$

Sonuç olarak, parsiyel rotator manşet yırtıkları, tam kat yırtıklar kadar ciddi klinik semptomlara neden olabilir. Tam kat yırtıklarda olduğu gibi parsiyel rotator manşet yırtıklarında da cerrahi dışı tedavilerden fayda görmezse artroskopik tamir yöntemleriyle başarılı klinik sonuçlar elde edilebilir. Patolojiyi ortaya koyup, uygun tedaviyi gerek cerrahi gerekse konservatif olarak planlayarak yapmak ve ardından uygun rehabilitasyon protokollerini vermek tedavinin ana hatlarıdır.

\section{KAYNAKLAR}

1. Codman EA. Rupture of the supraspinatus tendon. 1911. Clin Orthop 1990;254:3-26. Crossref

2. Somerson JS, Hsu JE, Gorbaty JD, Gee AO. Classifications inBrief: Goutallier classification of fatty infiltration of the rotator cuff musculature. Clin Orthop Relat Res 2016;474(5):1328-32. Crossref

3. Patte D. Classification of rotator cuff lesions. Clin Orthop Relat Res 1990;254:81-6. Crossref

4. Yamaguchi K, Ditsios K, Middleton WD, Hildebolt CF, Galatz LM, Teefey SA. The demographic and morphological features of rotator cuff disease. A comparison of asymptomatic and symptomatic shoulders. J Bone Joint Surg Am 2006;88(8):1699-704. Crossref

5. Krischak G, Gebhard F, Reichel H, Friemert B, Schneider F, Fisser $C$, et al. A prospective randomized controlled trial comparing occupational therapy with homebased exercises in conservative treatment of rotator cuff tears. J Shoulder Elbow Surg 2013;22(9):1173-9. Crossref

6. Millett PJ, Warth RJ, Dornan GJ, Lee JT, Spiegl UJ. Clinical and structural outcomes after arthroscopic single-row versus double-row rotator cuff repair: a systematic review and meta-analysis of level I randomized clinical trials. J Shoulder Elbow Surg 2014;23(4):586-97. Crossref
7. Chen M, Xu W, Dong Q, Huang Q, Xie Z, Mao Y. Outcomes of single-row versus double-row arthroscopic rotator cuff repair: a systematic review and meta-analysis of current evidence. Arthroscopy 2013;29(8):1437-49. Crossref

8. Kim DH, Elattrache NS, Tibone JE, Jun BJ, DeLaMora SN, Kvitne RS, et al. Biomechanical comparison of a single-row versus double-row suture anchor technique for rotator cuff repair. Am J Sports Med 2006;34(3):407-14. Crossref

9. Park JY, Lhee SH, Choi JH, Park HK, Yu JW, Seo JB. Comparison of the clinical outcomes of single- and double-row repairs in rotator cuff tears. Am J Sports Med 2008;36(7):1310-6. Crossref

10. Fermont AJ, Wolterbeek N, Wessel RN, Baeyens JP, de Bie RA. Prognostic factors for successful recovery after arthroscopic rotator cuff repair: a systematic literature review. J Orthop Sports Phys Ther 2014;44(3):153-63. Crossref

11. Lambers Heerspink FO, Dorrestijn O, van Raay JJ, Diercks RL. Specific patient-related prognostic factors for rotator cuff repair: a systematic review. J Shoulder Elbow Surg 2014;23(7):1073-80. Crossref

12. Cortes, Z.E., S.M. Hammerman, and G.M. Gartsman, Pulmonary embolism after shoulder arthroscopy: could patient positioning and traction make a difference? J Shoulder Elbow Surg 2007;16(2):p.E16-7. Crossref

13. Edgar R, Nagda S, Huffman R, Namdari S. Pulmonary embolism after shoulder arthroscopy. Orthopedics 2012;35(11):e1673-6. Crossref

14. Yamaguchi K. Mini-open rotator cuff repair: an updated perspective. Instr Course 2001;(50):53-61.

15. Lo IK, Burkhart SS. Transtendon arthroscopic repair of partial-thickness, articular surface tears of the rotator cuff. Arthroscopy 2004;20(2):214-20. Crossref

16. Shah MR, Strauss EJ, Kaplan K, Jazrawi L, Rosen J. Initial loop and knot security of arthroscopic knots using high-strength sutures. Arthroscopy 2007;23(8):884-8. Crossref

17. Demirhan M, Esenyel CZ. All arthroscopic treatment of rotator cuff tears. Acta Orthop Traumatol Turc 2003;37(1):93-104.

18. Dines J, Bedi A, ElAttrache NS, Dines DM. Single-row versus double-row rotator cuff Repair: techniques and outcomes J Am Acad Orthop Surg 2010;18(2):83-93. Crossref

19. Ide J, Maeda S, Takagi K. A comparison of arthroscopic and open rotator cuff repair. Arthroscopy 2005;21(9):1090-8. Crossref

20. Brislin KJ, Field LD, Savoie FH III. Complications after arthroscopic rotator cuff repair. Arthroscopy 2007;23(2):124-8. Crossref

21. Randelli P, Spennacchio P, Ragone V, Arrigoni P, Casella A, Cabitza P. Complications associated with arthroscopic rotator cuff repair: a literature review. Musculoskelet Surg 2012;96(1):9-16. Crossref

22. George MS, Khazzam M. Current concepts review: revision rotator cuff repair. J Shoulder Elbow Surg 2012;21(4):431-40. Crossref 
23. Yoon TH, Kim SJ, Choi YR, Cho JT, Chun YM. Arthroscopic revision rotator cuff repair: the role of previously neglected subscapularis tears. Am J Sports Med 2021;15:3635465211047485. crossref
24. Fan N, Yuan S, Du P, Wu Q, Li J, Kong X, et al.The effects of smoking on clinical and structural outcomes after rotator cuff repair: a systematic review and meta-analysis. J Shoulder Elbow Surg 202120:S1058-2746(21)00805-3. 